\title{
Halothane: how should it be used in a developing country?
}

\author{
N. Mahboobi, ${ }^{\text {S. Esmaeili, }{ }^{1} \text { S. Safari, }}{ }^{2}$ P. Habibollahi, ${ }^{3}$ A. Dabbagh ${ }^{4}$ and S-M. Alavian ${ }^{5}$
}

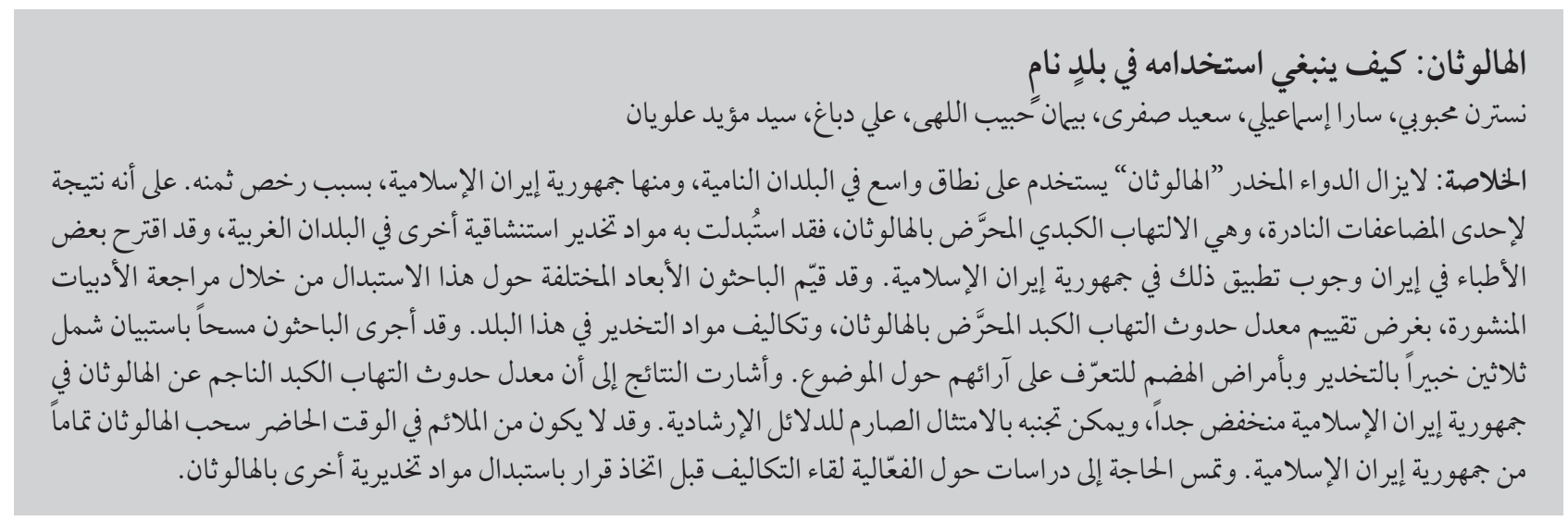

ABSTRACT The anaesthetic agent halothane is still widely used in developing countries including the Islamic Republic of Iran because of its low price. Because of halothane-induced hepatitis, a rare complication, it has been replaced by other inhalation anaesthetics in Western countries; it has been suggested by some Iranian professionals that the Islamic Republic of Iran should do the same. We evaluated various dimensions of this replacement through a literature review to assess the incidence of halothane-induced hepatitis and costs of anaesthetics in the country. We also conducted a questionnaire survey of 30 anaesthesiology/gastroenterology experts about their views on the subject. The results indicate that the incidence of halothane hepatitis in the Islamic Republic of Iran is very low and could mostly be avoided by strict adherence to guidelines. Complete withdrawal of halothane in the Islamic Republic of Iran might not be appropriate at present. Comprehensive cost-effectiveness studies are needed before a decision is made on complete replacement of halothane with other anaesthetics.

\section{Mode d'utilisation de l'halothane dans un pays en développement}

RÉSUMÉ L'utilisation de l'halothane en tant qu'agent anesthésique demeure très répandue dans les pays en développement, notamment en République islamique d'Iran, en raison de son faible coût. L'halothane pouvant entraîner l'apparition d'une hépatite, et bien qu'il s'agisse d'une complication rare, il a été remplacé par d'autres agents anesthésiques par inhalation dans les pays occidentaux. Certains professionnels iraniens ont suggéré que la République islamique d'Iran fasse de même. Nous avons évalué les divers aspects de ce remplacement en examinant la littérature scientifique pour connaître l'incidence des hépatites induites par l'halothane et le coût des anesthésiques dans le pays. Nous avons aussi soumis un questionnaire d'opinion à 30 experts en anesthésiologie et gastro-entérologie. Les résultats indiquent que l'incidence des hépatites induites par I'halothane en République islamique d'Iran est très faible, et que ces dernières pourraient généralement être évitées par le strict respect des directives. Le retrait total de l'halothane du pays paraît inapproprié à l'heure actuelle. Des études globales du rapport coût-efficacité sont requises avant toute décision sur son remplacement complet par d'autres anesthésiques.

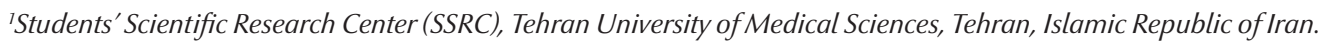

${ }^{2}$ Department of Anaesthesiology and Pain Medicine, Tehran University of Medical Sciences, Tehran, Islamic Republic of Iran.

${ }^{3}$ Department of Gastroenterology, Tehran University of Medical Sciences, Tehran, Islamic Republic of Iran.

${ }^{4}$ Anaesthesiology Research Center, Shahid Beheshti University of Medical Sciences, Tehran, Islamic Republic of Iran

${ }^{5}$ Department of Gastroenterology, Baqiyatallah University of Medical Sciences, Tehran, Islamic Republic of Iran (Correspondence to S-M. Alavian: alavian@thc.ir).

Received: 14/03/10; accepted: 23/06/10 


\section{Introduction}

Anaesthesia has been influential in different fields of medical practice, especially in surgical procedures and efforts have been ongoing over the years to find the most suitable anaesthetic agent. Halothane, which was considered to be a great advance in the field of anaesthesiology, was first introduced in 1956 [1]. Methoxyflurane was introduced in 1960 [2] and then enflurane [3], isoflurane [4], desflurane [5] and sevoflurane [6].

Some properties of halothane, such as having the lowest respiratory depression effect among inhalation anaesthetics and its low airway irritation, are very desirable and make it suitable for anaesthesia induction, while isoflurane and desflurane are so airway-irritant that they should not be used to induce anaesthesia [7]. However, complications have been reported following anaesthesia with halothane, especially halothaneinduced hepatitis $[8-11]$, and it has generally been phased out in western countries [12] Nevertheless, halothane is still in considerable use in developing countries as it is the least expensive inhalation anaesthetic and its minimum alveolar concentration (MAC) is less than other inhalation anaesthetics [7]. Because the majority of the world's population live in developing countries, halothane remains the most commonly used inhalation anaesthetic agent across the world [13]. Halothane is manufactured in many countries and one of the largest producers is India [13].

As mentioned above, hepatitis is the most significant complication of halothane anaesthesia and has 2 types. Type 1 is a mild hepatitis with an asymptomatic rise in liver enzymes, but type 2 manifests in the form of serious hepatotoxicity and is more likely to be associated with acute liver failure and death. However, this serious complication is relatively rare and occurs in 1 in 6000 to 1 in 35000 patients [14].
Arguments over halothane hepatitis began in the Islamic Republic of Iran in 2006 when a number of experts claimed that halothane should be considered a major health threat [10]. Consequently, under supervision of the Ministry of Health and Medical Education, several meetings were held in which gastroenterology and anaesthesiology experts evaluated the risks and benefits of the use of halothane in comparison with other available inhalation anaesthetics. They sought to come to a decision on whether or not halothane should continue to be used in the Islamic Republic of Iran and recommended further investigations (The National Healthcare Disparities Report) [13].

Because of considerable disagreement among physicians about the incidence of halothane hepatitis in the Islamic Republic of Iran, it took policymakers 3 years to clarify how inhalation anaesthetic agents should be used and they recommended further investigations and cost-benefit analyses (The National Healthcare Disparities Report) [13]. Accordingly, considering the post-exposure probability of hepatitis, it was indicated that halothane should not be used in patients with a history of multiple exposure to halothane, especially where there was evidence of previous mild reaction, family history of sensitization, obesity and age over 50 years [15]. Multiple exposures, especially at intervals of $<6$ weeks, positive history of jaundice or fever following anaesthesia, obesity, middle age, female sex, genetic predisposition and enzyme induction as a result of alcohol or barbiturate use have been demonstrated as risk factors of halothane-induced hepatitis [16]. To confirm some of these risk factors such as female sex, adult age and genetic predisposition, a murine model of halothane hepatitis was developed recently and resulted in production of reproducible severe hepatitis, with similar characteristics to human halothane hepatitis [17].
Although paying attention to risk factors could decrease the risk of halothane-induced hepatitis, some professionals have insisted on the necessity of complete replacement of halothane with other inhalation agents such as isoflurane, sevoflurane and desflurane. Due to a lack of discussion of different aspects of this problem, we aimed to evaluate the various dimensions of the process of halothane elimination in the Islamic Republic of Iran through a review of the literature and a national survey of experts.

\section{Methods}

\section{Literature review}

A literature review up to the year 2009 was undertaken on major electronic databases, including Medline (PubMed), Embase, Scopus, Institute for Scientific Information (ISI) and the Cochrane library. The searches were done using several predefined combinations of the following keywords and $\mathrm{MeSH}$ terms or their equivalents: halothane, hepatitis, anaesthetics, inhalation anaesthetics, sevoflurane, desflurane, isoflurane, enflurane and cost. While "Iran" was not used as a search term, 3 national databases of medical and life sciences literature including Scientific Information Database (SID), Iranmedex and Magiran were included. The final list of titles were obtained and abstracts were reviewed by 2 of the authors (N.M and S.E). Eligible studies were then identified with the use of critical appraisal tools [18] and their full texts obtained. Furthermore, bibliographies of eligible studies were screened for other relevant studies. Manuscripts that were included were relevant studies that were published in full in English or Farsi. The final decision on their eligibility was made by consensus.

\section{Questionnaire survey}

A questionnaire survey was also conducted among the 30 recognized 
anaesthesiology and gastroenterology experts in 2009 to determine their viewpoint on the necessary properties of the most appropriate inhalation anaesthetic agent for our country. All recruited experts were professors of medical universities of Tehran (Tehran University of Medical Sciences, Shahid Beheshti University of Medical Sciences, Iran University of Medical Sciences) and were members of the Iranian Anaesthesiologists' Association, who agreed to complete our questionnaire.

Our questionnaire included 10 open-ended questions focusing on costs and complications of halothane, isoflurane, sevoflurane and desflurane in relation to each other.

In addition, several meetings were held with some of the experts ( 10 meetings with 17 experts in total) who took part in the questionnaire survey (selected on the basis of their years of experience) with the aim of clarifying the different dimensions of the use of inhalation anaesthetics, such as their characteristics, costs and complications, and coming up with pragmatic solutions.

\section{Results}

\section{Literature review}

Even though a thorough search was performed to find relevant studies, no randomized clinical trial (RCT) concerning different economic and clinical issues between the use of various inhalation anaesthetics in Islamic Republic of Iran was found; nor in fact was any such RCT found anywhere else. However, conducting RCTs with the aim of comparing different anaesthetic agents with each other might not be possible because of ethical reasons. Thus, evidence from observational studies was considered and 21 papers were included for review. The most relevant national study was a retrospective case review of 59 halothane hepatitis cases that were reported over a 12-year period, between 1994 and 2006, from 7 Iranian hepatitis centres $[10]$.

Several factors might influence the reported cost of inhalation anaesthetics, such as the change in the cost of drugs over time as a result of competition amongst pharmaceutical companies. Hence accurate calculation of the direct and indirect costs of inhalation anaesthetics can be difficult $[19,20]$. Furthermore, results obtained from studies in one centre cannotbe generalized even to other institutes within the same country because of different costs they have to bear, such as different prices of drugs or personnel costs [21]. At the same time, factors like induction method, patient characteristics, hospitalization period, necessity of readmission in 3 months of discharge and necessity of admission to the intensive care unit have been shown to influence cost estimation [22].

Hepatitis following anaesthesia induced by other inhalation anaesthetics has also been reported although it is rare [23-25].
Table 1 shows costs of inhalation agents, reported by the food and drug deputy of the Ministry of Health and Medical Education in 2008 and 2009. The prices are in Iranian rials and US dollars and show that sevoflurane is much more expensive than halothane and isoflurane.

\section{Questionnaire survey}

The opinions of the professors on the properties needed for the most appropriate inhalation anaesthetic agent for the Islamic Republic of Iran are summarized in Table 2.

All participating experts considered halothane the cheapest anaesthetic agent because of its price, low minimum alveolar concentration and the less expensive vaporizers.

Eight experts believed that rapid recovery from anaesthesia induced by desflurane and sevoflurane may result in shorter periods of hospitalization and that might decrease the final costs. On the other hand, complications such as hyperthermia and hepatitis, which occur more often after halothane anaesthesia, may impose higher costs on the health system.

Ten experts stated that the act of replacing halothane with other inhalation anaesthetics cannot completely eliminate the risk of hepatitis and its consequent costs.

When professors were asked to choose the most suitable alternative in the Islamic Republic of Iran, the majority of them (23) proposed that it would

\begin{tabular}{|c|c|c|}
\hline \multirow[t]{2}{*}{ Anaesthetic name } & \multicolumn{2}{|c|}{ Price } \\
\hline & Rials & US\$ \\
\hline Halothane [Nicholas] $250 \mathrm{~mL}$ inhaler & 270700 & 20.82 \\
\hline Isoflurane [Halocarbon] $100 \mathrm{~mL}$ inhaler & 310000 & 23.84 \\
\hline Isoflurane [Minrad] $100 \mathrm{~mL}$ inhaler & 228000 & 17.57 \\
\hline Isoflurane [Nicholas] $100 \mathrm{~mL}$ inhaler & 235000 & 18.07 \\
\hline Isoflurane [Rhodia] $100 \mathrm{~mL}$ inhaler & 256700 & 19.74 \\
\hline Sevofluran [Abbott] $250 \mathrm{~mL}$ flacon for inhalation & 2876000 & 221.23 \\
\hline
\end{tabular}

Names in square brackets are the manufacturers. 


\begin{tabular}{|c|c|c|c|c|}
\hline Anaesthetic & Positive aspects & No. & Negative aspects & No. \\
\hline \multirow[t]{3}{*}{ Halothane } & $\begin{array}{l}\text { Lowest cost among inhalation } \\
\text { anaesthetics to purchase }\end{array}$ & 30 & Risk of halothane hepatitis & 30 \\
\hline & Suitable for induction & 30 & Risk of arrhythmia & 12 \\
\hline & $\begin{array}{l}\text { Use covered by health insurance } \\
\text { companies }\end{array}$ & 30 & Risk of hyperpyrexia & 11 \\
\hline \multirow[t]{2}{*}{ Isoflurane } & Low price & 21 & \multirow{2}{*}{$\begin{array}{l}\text { Risk of bronchospasm and therefore } \\
\text { not suitable for induction }\end{array}$} & \multirow[t]{2}{*}{20} \\
\hline & $\begin{array}{l}\text { Use covered by health insurance } \\
\text { companies }\end{array}$ & 30 & & \\
\hline \multirow[t]{4}{*}{ Sevoflurane } & Suitable for induction & 20 & Expensive & 20 \\
\hline & Rapid induction and recovery & 8 & Risk of nephrotoxicity & 2 \\
\hline & & & Risk of hepatitis & 1 \\
\hline & & & $\begin{array}{l}\text { Use not covered by health insurance } \\
\text { companies }\end{array}$ & 25 \\
\hline \multirow[t]{4}{*}{ Desflurane } & Suitable for maintenance & 17 & Most expensive inhalation anaesthetic & 30 \\
\hline & Rapid recovery & 8 & $\begin{array}{l}\text { Risk of laryngospasm and therefore } \\
\text { not suitable for induction }\end{array}$ & 21 \\
\hline & & & $\begin{array}{l}\text { Not available in the Islamic Republic } \\
\text { of Iran }\end{array}$ & 30 \\
\hline & & & No insurance coverage & 26 \\
\hline
\end{tabular}

be ideal to provide all operating rooms with a wide variety inhalation anaesthetics and give the anaesthesiologists the opportunity to select from of choices according to the circumstances.

\section{Discussion}

This study was performed to evaluate a decision made in the Islamic Republic of Iran to eliminate halothane and replace it with other inhalation anaesthetics such as isoflurane, sevoflurane and desflurane. Our results showed that no clinical trial or prospective study on inhalation anaesthetics, particularly their costs, has been performed in the Islamic Republic of Iran. Furthermore, studies done in other countries cannot be generalized to our country because of their obvious differences, for instance wide diversity of economic development.

The annual incidence of halothane hepatitis in the Islamic Republic of Iran was estimated to be very low as noted in a retrospective case review which identified 59 cases over 12 years with a mortality rate of $12.2 \%$ and no liver transplantation [10]. On the other hand, the majority of these 59 reported cases could have been avoided by strict adherence to established guidelines. For instance, 10 patients received halothane, although they had a previous history of halothane post-exposure reaction, which is a contraindication of using halothane [10].

Although a small number of reported halothane hepatitis cases in the Islamic Republic of Iran may be attributed to defects in the registry system whereby not all halothane hepatitis cases are being recorded, it can also be explained by the relatively low incidence of halothane hepatitis in this country. This claim is strengthened when one considers the large number of surgeries performed annually in the Islamic Republic of Iran. Although there is not an exact estimation, around 1 million patients undergo surgery each year and $90 \%$ to $95 \%$ of them are under general anaesthesia according to the statistics of the Ministry of Health and the Department of Anaesthesia of
Shahid Beheshti University of Medical Sciences (The National Healthcare Disparities Report). In addition, it has been demonstrated that more than $80 \%$ of hospitals use halothane in the Islamic Republic of Iran [10]. Hence, based on annual incidence of 4 cases, at least 44 cases of type 2 halothane hepatitis would be expected to occur annually in the Islamic Republic of Iran, while what has been reported in previous articles is far fewer (The Iranian National Healthcare Report, 2001). This small number, in addition to the considerable cost that would be imposed on the health system to replace halothane with other agents [13], should be kept in mind by policymakers.

It should also be taken into consideration that hepatitis can occur following administration of other inhalation anaesthetics. Thus, it is unlikely that treatment costs of probable hepatitis following anaesthesia can be completely eliminated by replacing halothane with other inhalation agents.

Analysis of the opinions of the experts in the survey showed that 


\section{Box 1 Contraindications and precautions for use of halothane}

\section{Contraindications}

- History of halothane post-exposure reaction

- History of recurrent exposure

- Positive family history of post-exposure reaction or halothane hepatitis

High-risk patients: halothane is not recommended in patients with $\geq 2$ of these risk factors

- Female gender

- $\geq 40$ years of age

- Obesity (body mass index $\geq 28 \mathrm{~kg} / \mathrm{m}^{2}$ )

- History of use of liver enzyme inducing drugs (e.g. phenobarbital)

controversy still exists among specialists about complete elimination of halothane. The majority of the specialists agreed that complete omission of halothane would impose enormous costs on the health system.

Actually, complete elimination of halothane in the Islamic Republic of Iran is not practicable because of the widespread distribution of this drug in nearly all operating rooms in our country, high number of operations performed annually, the inadequate insurance coverage for new anaesthetics, as well as low incidence of halothane hepatitis in the country. We would argue that all available inhalation agents should be provided in the Islamic Republic of Iran and they should be used appropriately according to the guidelines. In conclusion, we recommend to our colleagues that halothane not be used in contraindicated cases (Box 1). These contraindications have been defined by the Iranian Association of Gastroenterology and Hepatology, and we strongly support the introduction of a national registry database of all new cases of halothane-induced hepatitis for further decision-making.

To shed further light on this issue, a thorough cost-effectiveness analysis of halothane omission from the Islamic Republic of Iran's pharmacopoeia should be undertaken, taking into consideration the ethical dimensions of the matter. Consideration could be given to the possibility of explaining the characteristics and costs of the inhalation anaesthetics to the patients and letting them choose from the available options.

\section{References}

1. Johnstone M. The human cardiovascular response to fluothane anaesthesia. 1956. British Journal of Anaesthesia, 1998, 80:396405, discussion 395.

2. Whalen FX, Bacon DR, Smith HM. Inhaled anesthetics: an historical overview. Best Practice \& Research. Clinical Anaesthesiology, 2005, 19:323-330.

3. Black GW, Clarke RS. Recently introduced anesthetic drugs. International Anesthesiology Clinics, 1971, 9:171-196.

4. Stevens WC. New Halogenated Anesthetics: Enflurane and Isoflurane. California Medicine, 1972, 117:47.

5. Eger El 2nd. Partition coefficients of I-653 in human blood, saline, and olive oil. Anesthesia and Analgesia, 1987, 66:971-973.

6. Wallin RF et al. Sevoflurane: a new inhalational anesthetic agent. Anesthesia and Analgesia, 1975, 54:758-766.

7. Harper NJ. Inhalational anaesthetics. Anaesthesia and Intensive Care Medicine, 2004, 5:278-282.

8. Voigt MD et al. Halothane hepatitis in a South African population--frequency and the influence of gender and ethnicity. South African Medical Journal, 1997, 87:882-885.

9. Otedo AE. Halothane induced hepatitis: case report. East African Medical Journal, 2004, 81:538-539.
10. Eghtesadi-Araghi $\mathrm{P}$ et al. Halothane hepatitis in Iran: a review of 59 cases. World Journal of Gastroenterology, 2008, 14:5322-5326.

11. Kumar GP, Bhat VJ, Sowdi V. Fulminant hepatic failure following halothane anaesthesia. Journal ofClinical Forensic Medicine, 2005, 12:271-273.

12. What agents are available? Pharmacology, 2000, 11 (http:// www.nda.ox.ac.uk/wfsa/html/u11/u1115_02.htm accessed 1 November 2011).

13. Dabbagh A, Rajaei S. Halothane: Is there still any place for using the gas as an anesthetic? Hepatitis Monthly, 2011, 11(7):511-512..

14. Ray DC, Drummond GB. Halothane hepatitis. British Journal of Anaesthesia, 1991, 67:84-99.

15. Fallahian F. Halothane Induced Hepatitis (CME). Shiraz EMedical Journal, 2009, 10(4):209-220.

16. Perlata R et al. Halothane hepatotoxicity. (http://emedicine. medscape.com/article/166232-overview, accessed 2 November 2011).

17. Dugan $\mathrm{CM}$ et al. A mouse model of severe halothane hepatitis based on human risk factors. Journal of Pharmacology and Experimental Therapeutics, 2010, 333:364-372. 
18. EurasiaHealth Knowledge Network. Health Resources Digest. December 2006. Critical Appraisal Tools (http://www. eurasiahealth.org/attaches/99150/digest_Dec06_eng.pdf, accessed 14 December 2011).

19. Smith I et al. A multicentre comparison of the costs of anaesthesia with sevoflurane or propofol. British Journal of Anaesthesia, 1999, 83:564-570.

20. Lin CY, Wong CS, Wu CT. Cost analysis of three anesthetic regimens under auditory evoked potential monitoring in gynecologic laparoscopic surgery. Acta Anaesthesiologica Taiwanica, 2008. 46(1):53; author reply 53-4.

21. Schuster $\mathrm{M}$ et al. A retrospective comparison of costs for regional and general anesthesia techniques. Anesthesia and Analgesia, 2005, 100:786-794.
22. Jackson T, Myles PS. Part II: total episode costs in a randomized, controlled trial of the effectiveness of four anesthetics. Anesthesia and Analgesia, 2000, 91:1170-1175.

23. Martin JL et al. Hepatotoxicity after desflurane anesthesia. Anesthesiology, 1995, 83:1125-1129.

24. Lehmann A et al. Case report: fatal hepatic failure after aortic valve replacement and sevoflurane exposure. Canadian Journal of Anaesthesia, 2007, 54:917-921.

25. Carrigan TW, Straughen WJ. A report of hepatic necrosis and death following isoflurane anesthesia. Anesthesiology, 1987, 67:581-583.

\section{The WHO Essential Medicines Library}

The WHO Library on Essential Medicines provides a single point of entry for information about all medicines currently listed on the WHO Model List of Essential Medicines.

For each medicine on the List, there are links to clinical evidence about efficacy and safety, WHO or other clinical guidelines, and price information. For medicines that have been deleted from the List, the section on historical changes provides the rationale for changes.

The Library can be accessed at: http://apps.who.int/emlib/Defaultaspx?Language=EN 